\title{
STUDI PENGOLAHAN LIMBAH CAIR PENYAMAKAN KULITDI PT BUDI MAKMUR KECAMATAN GEDONG KUNING YOGYAKARTA TAHUN 2014
}

\author{
Sri Rezeki Indah Astiani*), Dr. Djamaluddin Ramlan, SKM, M.Kes ${ }^{\star *}$ )
}

\begin{abstract}
PT Budi Makmur is one of the made leather industry that located in Yogyakarta. It processing a raw leather which from goat leather that processed into wolves, shoes, etc. PT Budi Makmur also produce water waste that flows to the river and if the waste is not produced in the right way, the waste will be very dangerous for the ecosystem in that river.The aim of this research are to know the process of the liquid waste producing leather tanning, the parameter of the liquid waste before and after through the producing process (COD, BOD, TSS dan $\mathrm{pH}$ ), and the condition of the liquid waste producing leather tanning.

The kind of this research is descriptive. The research done by collecting the field data an laboratorium, and then analyzed and compared with the existing theory and quality of the liquid waste producing leather tanning.

The result show that the source of the waste produce from the leather tranning. Liquid waste that produced is about $8.000-12.000$ gallon per 1.000 wet leather pond that produced. The quality of the influent is BOD $1.946 \mathrm{mg} / \mathrm{lt}$, COD $1965 \mathrm{mg} / \mathrm{lt}$, TSS $1.774 \mathrm{mg} / \mathrm{ltd}$ and $\mathrm{pH} 7.50$. The quality of the effluent is BOD $98.61 \mathrm{mg} / \mathrm{lt}$, COD $100 \mathrm{mg} / \mathrm{t}$, TSS $1130 \mathrm{mg} / \mathrm{lt}$ and $\mathrm{pH} 7,49$. The step of the liquid waste processing are: filtering ink, equalitation ink, sedimentation, aeration and active mud.

The writer conclude that PT Budi Makmur has already optimal to decrease the content that contained in the leather-liquid waste producing but the effluent that is produced still exceed the exsisting standart quality. The suggestion to PT Budi Makmur is to more care about the liquid waste producing.
\end{abstract}

Refferences : 25 (1987-2012)

Keyword : made leather industry

Classification :-

*) Alumni Mahasiswa Jurusan Kesehatan Lingkungan Purwokerto

${ }^{* *}$ ) Dosen Jurusan Kesehatan Lingkungan Purwokerto

\section{PENDAHULUAN}

\section{A. Latar Belakang}

Industri adalah kegiatan ekonomi yang mengolah bahan mentah, bahan baku, barang setengah jadi, dan/atau barang jadi menjadi barang dengan nilai yang lebih tinggi untuk penggunaannya, termasuk kegiatan rancang bangun dan perekayasaan industri. Selain menghasilkan bahan jadi juga menghasilkan limbah, baik padat maupun cair yang bila tidak dikelola dengan baik dapat mengakibatkan masalah bagi manusia dan lingkungan sekitar. Industri penyamakan kulit yang berada di desa Gedong Kuning Yogyakarta mengolah bahan kulit mentah menjadi bahan kulit siap pakai. Dalam proses pengolahan limbah sebagai hasil akhir dari kegiatan produksi dikelola dengan menggunakan pengolahan limbah namun kenyataannya limbah yang dibuang mengakibatkan badan air menjadi kotor dan berbau.
Limbah adalah zat atau bahan buangan yang dihasilkan dari proses kegiatan manusia (Ign Suharto, 2011 :226). Limbah dapat berupa tumpukan barang bekas, sisa kotoran hewan, tanaman, atau sayuran. Keseimbangan lingkungan menjadi terganggu jika jumlah hasil buangan tersebut melebihi ambang batas toleransi lingkungan. Apabila konsentrasi dan kuantitas melibihi ambang batas, keberadaan limbah dapat berdampak negatif terhadap lingkungan terutama bagi kesehatan manusia sehingga perlu dilakukan penanganan terhadap limbah. Tingkat bahaya pencemaran yang ditimbulkan oleh limbah bergantung pada jenis dan karakteristik limbah.

Limbah yang dihasilkan di PT Budi Makmur yaitu limbah padat seperti sisa-sisa potongan kulit, bulu-bulu yang di hasilkan dari kulit hewan tersebut dan limbah cair yang seperti air sisa pencucian kulit, air sisa perendaman kulit, air garam, air bekas cuci, tetesan dan tumpahan.Industri penyamakan kulit di PT Budi Makmur melakukan proses 
pengolahan limbah sebelum dibuang ke badan air.

Tahapan pengolahan limbah cair pengolahan kulit yaitu: kulit di pilih kemudian di rendam, penghilangan zat kapur, proses pencucian, proses pengasaman, proses pemutihan, proses pencucian, proses pemucatan. Tahapan pengolahan limbah cair sebagai berikut: air buangan masuk ke bak penampungan, melalui proses lumpur aktif, ke bak filtrasi.Hasil akhir dari proses pengolahan limbah cair penyamakan kulit di PT Budi Makmur Kecamatan Gedong Kuning belum maksimal untuk yang di buang ke badan air berwarna hitam, berbau busuk dan mengakibatkan berkurangnya biota air seperti ikan.

Berdasarkan latar belakang tersebut peneliti tertarik untuk melakukan penelitian dengan judul "Studi Pengolahan Limbah Cair Penyamakan Kulit di PT Budi Makmur Kecamatan Gedong Kuning Yogyakarta Tahun 2014". Penulis berharap hasil penelitian dapat menjadi masukan bagi pihak industri untuk mengatasi masalah pencemaran lingkungan akibat limbah cair industri penyamakan kulit.

\section{B. Perumusan Masalah}

Bagaimana hasil pengolahan limbah cair penyamakan kulit di PT Budi Makmur Kecamatan Gedong Kuning Yogyakarta?

\section{Tujuan Penelitian}

1. Tujuan umum

Mendiskripsikan pengolahan limbah cair pada industri penyamakan kulit di PT Budi Makmur Kecamatan Gedong Kuning Yogyakarta.

2. Tujuan khusus

a. Mendiskripsikan tahapan proses pengolahan limbah cair penyamakan kulit di PT Budi Makmur Kecamatan Gedong Kuning Yogyakarta.

b. Mendiskripsikan sumber daya yang ada untuk proses pengolahan limbah cair penyamakan kulit di PT Budi Makmur Kecamatan Gedong Kuning Yogyakarta.

c. Mengetahui prosentase penurunan parameter limbah cair sebelum dan sesudah melalui proses pengolahan limbah cair penyamakan kulit di PT Budi Makmur Kecamatan Gedong Kuning Yogyakarta.

\section{Manfaat Penelitian}

1. Bagi Masyarakat

Memberikan informasi kepada masyarakat sekitarnya dan pengusaha home industri mengenai pentingnya Unit pengolahan limbah cair penyamakan kulit.

2. Bagi Pemilik

Memberikan masukan kepada pemilik tentang penanganan limbah cair penyamakan kulit di Unit Pengolahan Limbah.

3. Bagi Instituti

Dapat menjadi bahan bacaan di perpustakaan.

4. Bagi Peneliti

Sebagai bahan tambahan pengetahuan dan pengalaman dalam penulisan karya tulis ilmiah.

\section{METODE PENELITIAN}

\section{A. Kerangka Pikir}

1. Komponen Penyusun

a. Input

Masukan dalam konsep ini adalah limbah cair yang dihasilkan dari proses penyamakan kulit.

b. Proses

Proses dalam konsep ini adalah pengelolaan limbah cair pada penyamakan kulit.

c. Output

Kualitas/mutu limbah cair penyamakan kulit setelah melalui proses pengolahan.

\section{Gambar Kerangka Pikir}

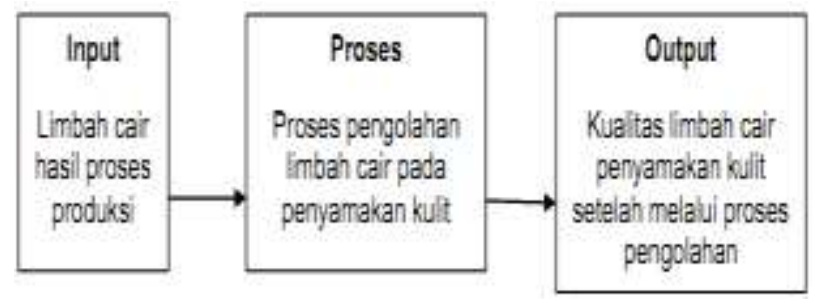

\section{B. Jenis Penelitian}

Jenis penelitian yang digunakan adalah analisis diskriptif dengan pendekatan evaluasi.

\section{Ruang Lingkup}

1. Waktu penelitian

a. Tahap persiapan : November 2013 Januari 2014

1) Penentuan masalah penelitian

2) Perumusan judul

3) Pembuatan proposal 
b. Tahap pelaksanaan : Januari- Februari 2014

1) Seminar proposal

2) Pengumpulan data

3) Survei ke lokasi penelitian

c. Tahap Penyelesaian : Maret - April 2014

1) Pengolahan data

2) Analisis data

3) Penyusunan $\mathrm{KTI}$

4) Perbaikan KTI

2. Lokasi

Peneliian ini dilakukan di PT Budi Makmur Kecamatan Gedong Kuning Kota Yogyakarta.

3. Materi

Pengolahan Limbah Cair Penyamakan Kulit.

\section{Subyek Penelitian}

Subyek penelitian ini adalah limbah cair yang dihasilkan dari proses penyamakan kulit.

\section{E. Pengumpulan Data}

Metode pengumpulan data yang digunakan dalam penelitian ini adalah sebagai berikut:

1. Jenis data
a. Data umum
Data umum berupa letak geografis, struktur organisasi PT Budi Makmur Yogyakarta.
b. Data khusus
Data khusus dalam penelitian ini, deskripsi pengolahan limbah cair penyamakan kulit, sumber daya, parameter kualitas air limbah.

2. Sumber data
a. Data primer
Data primer adalah data yang diperoleh secara langsung. Data primer penelitian ini adalah proses pengolahan limbah cair penyamakan kulit di PT Budi Makmur Yogyakarta.
b. Data sekunder
Data sekunder adalah data yang berasal dari sumber data yang tersedia sebelumnya. Data sekunder ini diperoleh dari Laboratorium Kesehatan Daerah Purbalingga.

3. Cara pengumpulan data Cara mengumpulkan data penelitian ini yaitu dengan cara:

a. Melakukan observasi dan wawancara sumber air limbah.

b. Pengukuran parameter kualitas air limbah.

\section{Instrumen pengumpul data Instrumen pengumpulan data ini menggunakan kuesioner dan observasi.}

\section{F. Analisis Data}

Analisis data menggunakan analisis deskriptif yaitu mendeskripsikan hasil dan menyajikan dalam bentuk tabel.

\section{HASIL}

\section{A. Gambaran Umum}

1. Sejarah singkat perusahaan

PT Budi Makmur berdiri sejak tahun 1966 di Yogyakarta, kota itu sendiri merupakan pusat industri kulit di Indonesia dan terkenal sebagai tempat utama dengan bahan dasar kulit yang bagus. Yogyakarta menjadi pusat industri kulit dan juga berada di kota dengan perguruan tinggi yang terkenal.

PT Budi Makmur memiliki luas tanah kurang lebih 30.000 meter persegi. Mesin yang digunakan PT Budi Makmur menggunakan mesin dari Itali, Jerman dan Jepang. Mesin yang digunakan sangatlah canggih karena dapat menghasilkan samakan kulit yang bagus. Hasil penyamakan kulit PT Budi Makmur merupakan salah satu hasil dengan kualitas terbaik.

Awal mula PT Budi Makmur mengolah kulit sapi dan kambing, namun hasil yang dihasilkan lebih bagus kulit kambing dibanding dengan kulit sapi. Untuk itu PT Budi Makmur lebih dominan pada kulit kambing. Kulit kambing yang disamakkan menghasilkan sarung tangan, sepatu, tali kacamata renang.

PT Budi Makmur juga telah mendapatkan sertifikat ISO 9001 pada tahun 2000. Hasil penyamakan kulit yang dihasilkan PT Budi Makmur juga sudah di export keluar negeri, seperti Itali, Jerman, Spanyol, Cina dan Singapore.

2. Letak geografis PT Budi Makmur

PT Budi Makmur adalah salah satu pabrik penyamakan kulit yang berada di Daerah Istimewa Yogyakarta yang berlokasi di Jalan Peleman Rejowinangun Yogyakarta, tepatnya di kawasan wisata kebun binatang Gembira Loka. Luas tanah PT Budi Makmur kurang lebih 30.000 meter persegi. 
3. Struktur organisasi

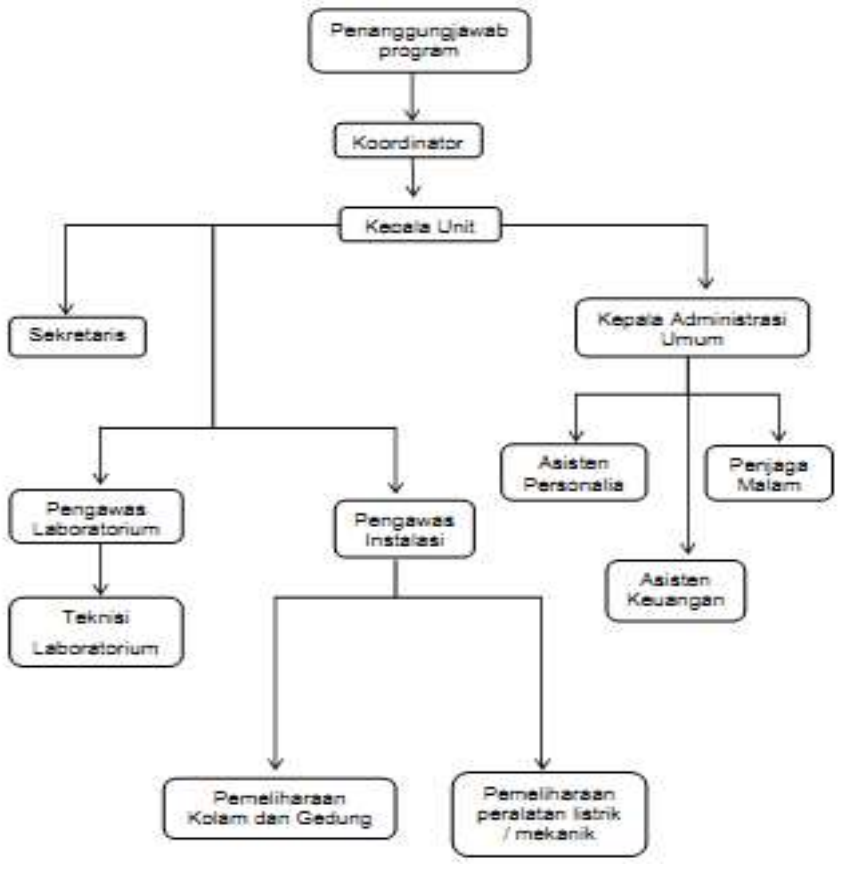

Gambar 4.1

Struktur Organisasi PT Budi Makmur Kecamatan Gedong Kuning Yogyakarta

4. Deskripsi Pengolahan Limbah Cair

Pengolahan limbah cair penyamakan kulit di PT Budi Makmur menggunakan proses pengolahan secara fisika dan biologi dan tidak menggunakan proses secara kimia, maka pengolahan air limbah penyamakan kulit di PT Budi Makmur dapat dikelompokkan sebagai berikut :

a. Pengolahan pendahuluan (pre treatment)

Pengolahan pendahuluan yang digunakan yaitu saringan. Air sisa produksi semua tercampur jadi satu tidak ada pemisahan. Air sisa produksi penyamakan kulit berjumlah 8.000-12.000 galon tiap 1.000 pond kulit basah yang diproses. Kandungan limbah rata-rata $8.000 \mathrm{ppm}$ total padatan, $1.000 \mathrm{ppm}$ protein, $300 \mathrm{ppm}$ $\mathrm{NaCl}, 1.600 \mathrm{ppm}$ total kesadahan, 1.000 ppm sulfida, 40 ppm kromium, dan $60 \mathrm{ppm}$ nitrogen. Bak penyaring ini berfungsi untuk menyaring limbah padat yang masih terbawa air buangan. Bak penyaring ini terdiri dari 2 saringan yaitu saringan kasar untuk menyaring kulit, sedangkan saringan halus untuk menyaring padatan seperti bulu-bulu halus yang masih terbawa air. b. Pengolahan pertama (primary treatment)

Pengolahan pertama adalah pengolahan yang bertujuan untuk mengurangi zat padat tercampur di dalam air limbah melalui pengendapan hal ini di maksudkan untuk mengendapkan kandungan krom yang ada. Lumpur yang kaya dengan endapan krom ini dipisahkan dengan menggunakan klarifer. Cairan dari klarifer di alirkan ke bak equalisasi untuk dicampur dengan limbah lain yang tidak mengandung krom.

c. Pengolahan kedua (secondary treatment)

$$
\text { Pengolahan kedua yang }
$$

digunakan dalam pengolahan air limbah di PT Budi Makmur adalah chemical proses yaitu meliputi koagulasi dan flokulasi. Setelah melewati bak koagulasi-flokulasi kemudian limbah cair mengalir ke bak pengendap pertama kemudian menuju cooling tower untuk mendinginkan limbah cair agar bakteri pengurai limbah cair memiliki suhu optimal, setelah itu lanjut ke bak aerasi.

d. Pengolahan lanjut (ultimate disposal)

Pengolahan lanjut yang digunakan dalam pengolahan air limbah di PT Budi Makmur adalah pengolahan lumpur aktif (pengering lumpur).

5. Sumber Daya Pengolahan Limbah Cair

a. Tenaga Pengolah

Tenaga pengolah limbah cair atau petugas pengolah limbah cair di PT Budi Makmur berjumlah 17 orang. Masing-masing petugas sudah mempunyai tanggungjawab sendirisendiri. Petugas sudah berpengalaman dalam masalah pengolahan limbah cair penyamakan kulit. Jumlah keseluruhan pegawai di PT Budi Makmur adalah 150 orang.

b. Alat Pengolahan Limbah Cair

Untuk mendapatkan hasil samakan kulit yang bagus, maka PT Budi Makmur juga menyediakan alatalat yang canggih pula. Alat-alat yang digunakan dalam proses penyamakan kulit diantaranya : mesin pencukur/ pemotong, rotary drum, mesin pressing. Adapun bak-bak pengolah limbah cair di PT Budi Makmur yaitu : bak pengumpul, bak penyaring, bak 
equalisasi, bak koagulasi-flokulasi, bak pengendap, cooling tower, bak aerasi dan bak pengering lumpur.

c. Bahan Pengolahan Limbah Cair

Pengolahan limbah cair sendiri menggunakan bahan-bahan seperti : larutan kapur, asam lemah, larutan garam, asam sulfur, krom sulfat, pewarna, minyak emulsi dan tanin sintesis. Bahan-bahan yang digunakan memiliki kegunaan dan fungsi yang berbeda-beda. Takaran untuk masingmasing larutan juga berbeda-beda tergantung kebutuhan.

6. Parameter Limbah Cair

Hasil pemeriksaan COD, BOD, TSS dan $\mathrm{pH}$ sebelum dan sesudah melalui proses pengolahan air limbah di PT Budi Makmur, Yogyakarta bulan Juni tahun 2014 dapat dilihat pada tabel 4.1.

Tabel 4.1:COD, BOD, TSS dan pH Sebelum Dan Sesudan Melalui Proses Pengolahan Limbah Cair Di PT Budi Makmur Pada Bulan Juni 2014.

\begin{tabular}{|c|c|c|c|c|c|}
\hline \multirow[t]{2}{*}{ No } & \multirow[t]{2}{*}{ Parameter } & \multirow{2}{*}{$\begin{array}{c}\text { Sebelum melalu } \\
\text { proses } \\
\text { pengolahan } \\
\text { (molit) }\end{array}$} & \multirow{2}{*}{$\begin{array}{l}\text { Setelah melalui } \\
\text { proses } \\
\text { pengolahan } \\
\text { (mglit) }\end{array}$} & \multicolumn{2}{|c|}{$\begin{array}{c}\text { Selisih } \\
\text { (penurunan) }\end{array}$} \\
\hline & & & & Mgilt & $\%$ \\
\hline 1. & $C O D$ & 1.965 & 100 & 1.805 & 94,91 \\
\hline 2 & $\mathrm{BOD}$ & $1.946,06$ & 98,61 & $1.847,45$ & 94,93 \\
\hline 3. & TSS & 1.774 & 1130 & 644 & 36,30 \\
\hline 4. & $\mathrm{pH}$ & 7,50 & 7,49 & 0,01 & 0,13 \\
\hline
\end{tabular}

\section{B. Gambaran Khusus}

\section{Sumber Limbah Cair}

Sumber limbah cair penyamakan kulit berasal dari hasil pengolahan kulit basah menjadi bahan kulit jadi yang siap untuk di proses menjadi sarung tangan , sepatu, tali kacamata renang. Limbah yang dihasilkan berupa cairan sisa crom, zat kapur dan bahan-bahan lain yang digunakan dalam proses penyamakan kulit.

2. Tahapan Proses Pengolahan Limbah Cair Penyamakan Kulit

Proses pengolahan limbah cair penyamakan kulit di PT Budi Makmur menggunakan proses pengolahan secara fisika dan biologi dan tidak menggunakan proses secara kimia, maka pengolahan air limbah penyamakan kulit di PT Budi Makmur dapat dikelompokkan sebagai berikut : Berdasarkan data yang diperoleh secara garis besar proses dan tahapan pengolahan limbah cair pada PT Budi Makmur dapat digambarkan seperti gambar 4.1
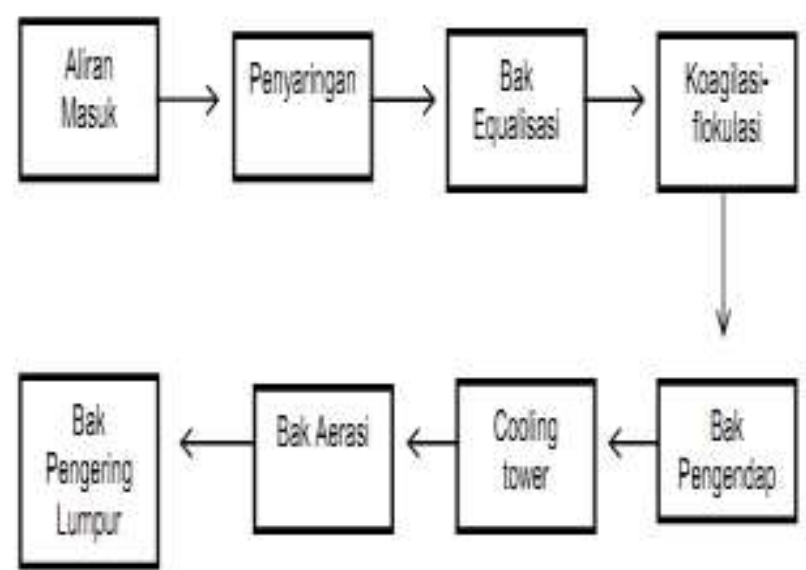

Gambar 4.2

Diagram Alur Proses Pengolahan Limbah Cair Penyamakan Kulit PT Budi Makmur, Yogyakarta

a. Aliran Masuk (Influent)

Limbah cair dari proses produksi penyamakan kulit kemudian dialirkan ke bak inlet pengolahan limbah cair PT Budi Makmur melalui saluran pipa tertutup.

b. Penyaringan

Limbah cair penyamakan kulit dari bak inlet disaring menggunakan dua buah saringan yaitu saringan kasar dan saringan halus. Saringan kasar berfungsi untuk memisahkan padatan yang berukuran besar dalam air limbah penyamakan kulit seperti potongan kulit, sedangkan saringan halus berfungsi untuk menyaring padatan yang lebih halus seperti bulu. Saringan ini berbentuk jeruji-jeruji. Proses penyaringan menjadi penting untuk memudahkan proses pengolahan air limbah, melindungi peralatan mekanik dari kerusakan karena adanya air limbah yang masih mengandung padatan serta menghindari terjadinya penyumbatan pada sistem distribusi air limbah.

c. Bak Equalisasi

Air limbah yang telah disaring selanjutnya di alirkan ke bak equalisasi. Bak ini berfungsi untuk menampung air limbah dan menghomogenkan atau menetralkan air limbah dengan pemberian $\mathrm{H} 2 \mathrm{SO} 4$ jika $\mathrm{pH}$ terlalu tinggi dan $\mathrm{NaOH}$ jika $\mathrm{pH}$ air terlalu rendah. Limbah dari bak equalisasi kemudian dipompa ke ke unitunit berikutnya agar aliran stabil. Pengadukan dilakukan menggunakan mixer. Terdapat 4 bak equalisasi, namun hanya 2 bak yang berfungsi atau digunakan. Bak ini 
terbuat dari beton dengan ukuran diameter $30 \mathrm{~m}$ dan tinggi $5 \mathrm{~m}$, dengan kapasitas 25m3/jam. Bak equalisasi ini memiliki temperatur $40^{\circ} \mathrm{C}-43^{\circ} \mathrm{C}$ dengan waktu tinggal 30 menit.

d. Chemical Proses

Selain penanganan berupa penambahan bahan kimai $\mathrm{H} 2 \mathrm{SO} 4$ atau $\mathrm{NaOH}$, terjadi pula proses yang dinamakan proses koagulasi dan flokulasi.

1) Koagulasi

Proses ini menggunakan dua buah bak yang dilengkapi pengaduk cepat dalam setiap baknya dan ditambahkan koagulan. Koagulan ini akan mengikat partikel-partikel halus untuk membentuk flok-flok yang mampu mengendap di primary clarifer. bak koagulan ini memiliki ukuran dengan $\mathrm{p}=3 \mathrm{~m}, \mathrm{l}=2 \mathrm{~m}, \mathrm{t}=5 \mathrm{~m}$ dengan volume $=30 \mathrm{~m} 3$ dengan waktu tinggal 1 jam.

2) Flokulasi

Proses ini menggunakan dua buah bak yang dilengkapi satu buah pengaduk dengan kecepatan rendah setiap baknya. Apabila diperlukan, pada tahap ini ditambahkan flokulan (polimer). Bak flokulasi ini memiliki ukuran hampir sama dengan bak koagulasi hanya berbeda tinggi, bak flokulasi ini memiliki tinggi 6 , adapun waktu tinggal pada bak ini adalah 1 jam.

e. Bak Pengendap

Air limbah yang telah membentuk flok mengalir ke primary clarifer dan mengendap secara gravitasi. Endapan yang terjadi akan disapu oleh scraper menuju center column yang selanjutnya dipompa ke belt press. Airnya dipompa ke cooling water untuk didinginkan. Bak ini terbuat dari semen beton dengan ukuran $\mathrm{d}=36 \mathrm{~m}, \mathrm{~h}=4,5 \mathrm{~m}, \mathrm{v}=$ $4.500 \mathrm{~m}^{3}$ dengan waktu tinggal 2-4 jam.

f. Cooling Tower

Air yang dipompa dari bak pengendap didinginkan di cooling tower sampai suhu dibawah $37^{\circ} \mathrm{C}$. Suhu air limbah harus diturunkankarena bakteri pengurai limbah memiliki suhu optimalhidupnya pada $370 \mathrm{o}$, diatas suhu tersebut bakteri akan shock bahkan mati. Pendinginan dilakukan dengan menggunakan exhouse fan yang berfungsi untuk menyedotudara panas dari air yang dijatuhkan melalui sirip-sirip cooling tower sehingga air yang jatuh berbentuk butiran-butiran kecil. Air limbah yang telah didinginkan akan mengalir ke bak aerasi untuk memperoleh perlakuan biologi. g. Bak Aerasi

Bak Aerasi berisi air limbah yang bercampur dengan lumpur aktif. Lumpur aktif merupakan lumpur bakteri yang berfungsi untuk mengolah limbah. Di bak aerasi akan terjadi proses degradasi senyawa organik dalam air limbah oleh bakteri. Bak aerasi di PT Budi Makmur dilengkapi dengan 11 aerator yang dicelupkan dan dua buah mixer yang tidak disuplai oksigen. Aerator yang dicelupkan berfungsi untuk memecah udara menjadi gelembung-gelembung udara yang lebih kecil, sedangkan sebagai sumber oksigen digunakan roots blower sebanyak 3 unit. Urea dan bakteri guard ditambahkan sebagai nutrisi bagi mikroorganisme pengurai limbah. Adapun waktu tinggal pada bak aerasi adalah 8 jam.

h. Bak Lumpur Pengering

Lumpur yang dihasilkan pada bak aerasi kemudian masuk ke dalam bak lumpur pengering. Bak lumpur pengering ini berfungsi untuk mengeringkan lumpur sisa hasil pengolahan penyamakan kulit. Lumpur yang sudah kering bisa dimanfaatkan kembali untuk dibuat bahan baku batako.

\section{PEMBAHASAN}

\section{A. Gambaran Umum}

Sebagai salah satu industri penyamakan kulit PT Budi Makmur terkenal dengan hasil penyamakan kulit yang bagus. Untuk mengurangi dampak yang ditimbulkan oleh limbah cair pada badan air upaya yang dilakukan oleh PT Budi Makmur yaitu dengan membangun Instalasi Pengolahan Air Limbah di PT Budi Makmur, dan juga rutin memeriksakan kandungan yang ada pada limbah cair penyamakan kulit.

Jenis limbah yang dikeluarkan PT Budi Makmur juga harus tidak melebihi ambang batas, untuk itu PT Budi Makmur rutin memeriksa limbah cairnya tersebut. Limbah cair penyamakan kulit itu sendiri diperiksa rutin setiap satu bulan dua kali oleh BBTKL Yogyakarta. Pemeriksaan dilakukan awal bulan dan akhir bulan. Pemeriksaan limbah cair penyamakan kulit meliputi pemeriksaan COD, BOD, TSS, $\mathrm{pH}$.

Bahan organik dan krom dari limbah cair penyamakan kulit merupakan sumber pencemar yang dapat menurunkan kualitas air sungai. Ditinjau dari parameter COD dan BOD di Sungai Gajahwong, dalam pemantauan 2001 mengalami perubahan 
yang fluktuatif dibagian hulu, tengah maupun hilir. Perubahan yang terjadi adalah kenaikan kualitas parameter COD dan BOD di daerah hulu dan hilir, sedangkan di daerah tengah mengalami penurunan, namun sudah melampaui nilai ambang batas (NAB) yang dipersyaratkan. PT. Budi Makmur menetapkan baku mutu limbah cair untuk industri penyamakan kulit mengacu pada surat Keputusan Gubernur DIY No.214 /KPTS/1991 tentang baku mutu limbah cair penyamakan kulit.

\section{B. Gambaran Khusus}

1. Sumber Limbah Cair Penyamakan Kulit Sumber limbah cair penyamakan kulit di PT Budi Makmur adalah dari seluruh proses produksi penyamakan kulit. Semua limbah yang berasal dari proses penyamakan kulit di PT Budi Makmur langsung masuk ke dalam bak penampungan, kemudian melalui proses penyaringan dan equalisasi, kemudian masuk ke bak pengendap, selanjutnya mengalir ke bak aerasi dan yang terakhir ke bak pengeringan lumpur. Limbah cair penyamakan kulit yang dihasilkan PT Budi Makmur langsung dialirkan ke sungai Gajahwong. PT Budi Makmur menetapkan baku mutu limbah cair penyamakan kulit yang mengacu pada Surat Keputusan Gubernur DIY No.214 /KPTS/1991 tentang Baku Mutu Limbah Cair Penyamakan Kulit, disebutkan bahwa ada beberapa parameter penting yang menjadi suatu indikator tingkat pencemaran lingkungan untuk limbah cair penyamakan kulit, diantaranya adalah:

a. COD

Chemical Oxygen Demand (COD) merupakan ukuran bagi pencemaran air oleh zat-zat organik yang secara alamiah dapat dioksidasikan melalui proses mikrobiologis dan mengakibatkan berkurangnya oksigen terlarut di dalam air. Kadar maksimum COD dalam limbah cair penyamakan kulit menurut Surat Keputusan Gubernur DIY No.214 /KPTS/1991 adalah $110 \mathrm{Mg} / \mathrm{lt}$

b. BOD

Biological OxygenDemand (BOD) atau Kebutuhan Oksigen Biologi kadar maksimum dalam limbah cair penyamakan kulit menurut Surat Keputusan Gubernur DIY No.214 /KPTS/1991 adalah 50 Mg/lt c. TSS

Total Suspended Solid (TSS) didefinisikan sebai padatan yang menyebabkan kekeruhan air dan pendangkalan badan air jika langsung dibuang ke badan air. Kadar maksimum TSS dalam limbah cair penyamakan kulit menurut Surat Keputusan Gubernur DIY No.214 /KPTS/1991 adalah $60 \mathrm{Mg} / \mathrm{lt}$

d. $\mathrm{pH}$

$\mathrm{pH}$ menunjukkan kadar asam atau basa dalam suatu larutan melalui konsentrasi (sebelum aktivitas) ion hidrogen $\mathrm{H}+$. Batas maksimum $\mathrm{pH}$ limbah cair penyamakan kulit menurut Surat Keputusan Gubernur DIY No.214 /KPTS/1991 adalah 6,0-9,0

2. Hasil Pemeriksaan Parameter Air Limbah a. COD (Chemical Oxygen Demand)

Kadar COD inlet air limbah sebesar $1.965 \mathrm{mg} / \mathrm{lt}$ dengan COD outlet air limbah sebesar $100 \mathrm{mg} / \mathrm{lt}$. Kadar maksimum COD dalam limbah cair penyamakan kulit menurut Surat Keputusan Gubernur DIY No.214 /KPTS/1991 adalah $110 \mathrm{mg} / \mathrm{lt}$. Dengan proses pengolahan air limbah di PT Budi Makmur terjadi penurunan kadar COD sebanyak $1.865 \mathrm{mg} / \mathrm{t}$, artinya proses pengolahan air limbah berfungsi dan apabila dibandingkan dengan Surat Keputusan Gubernur DIY No.214 /KPTS/1991 pengolahan air limbah sudah baik. Namun belum maksimal karena masih ada sisa kadar COD yang bisa membahayakan ekosistem yang lain, sehingga perlu dilakukan perbaikan.

b. BOD (Biologycal Oxygen Demand)

BOD inlet air limbah sebesar $1.946,06 \mathrm{mg} / \mathrm{tt}$ dengan BOD outlet air limbah sebesar 98,61 mg/lt. Kadar maksimum BOD dalam limbah cair penyamakan kulit menurut Surat Keputusan Gubernur DIY No.214 /KPTS/1991 adalah 50 mg/tt. Dengan proses pengolahan air limbah di PT Budi Makmur terjadi penurunan kadar BOD sebanyak $1.847,45 \mathrm{mg} / \mathrm{tt}$, artinya proses pengolahan air limbah berfungsi dan apabila dibandingkan dengan Surat Keputusan Gubernur DIY No.214 /KPTS/1991 pengolahan air limbah tidak baik karena masih melebihi baku mutu libah cair yang ada. Maka perlu dilakukan pengawasan terhadap pengolahan 
limbah cair dan perlu dilakukan perbaikan.

c. TSS (Total Suspended Solid) Kadar TSS inlet air limbah sebesar $1.774 \mathrm{mg} / \mathrm{lt}$ dengan TSS outlet air limbah sebesar $1.130 \mathrm{mg} / \mathrm{lt}$. Kadar maksimum TSS dalam limbah cair penyamakan kulit menurut Surat Keputusan Gubernur DIY No.214 /KPTS/1991 adalah 60 mg/lt. Dengan proses pengolahan air limbah di PT Budi Makmur terjadi penurunan kadar TSS sebanyak $644 \mathrm{mg} / \mathrm{lt}$, artinya proses pengolahan air limbah berfungsi dan apabila dibandingkan dengan Surat Keputusan Gubernur DIY No.214 /KPTS/1991 pengolahan air limbah tidak baik karena masih melebihi baku mutu limbah cair yang ada. Maka perlu dilakukan pengawasan terhadap pengolahan limbah cair dan perlu dilakukan perbaikan.

d. $\mathrm{pH}$

$\mathrm{pH}$ inlet air limbah sebesar 7,50 dengan $\mathrm{pH}$ outlet air limbah sebesar 7,49. $\mathrm{pH}$ effluen limbah cair yang dibuang ke sungai $\mathrm{pH} 7,48$. $\mathrm{pH}$ effluen ini masih masuk kisaran baku mutu $\mathrm{pH}$ yang ditetapkan menurut Surat Keputusan Gubernur DIY No.214 /KPTS/1991 yaitu 6,0-9,0

3. Proses Pengolahan Limbah Cair Penyamakan Kulit

Proses pengolahan limbah cair penyamakan kulit di PT Budi Makmur menggunakan proses pengolahan secara fisika biologi dan tidak menggunakan proses secara kimia, maka pengolahan air limbah penyamakan kulit di PT Budi Makmur dapat dikelompokkan sebagai berikut :

a. Influent

Limbah cair dari proses produksi penyamakan kulit kemudian dialirkan ke bak inlet pengolahan limbah cair PT Budi Makmur melalui saluran pipa tertutup.

b. Penyaringan

Limbah cair penyamakan kulit dari bak inlet disaring menggunakan dua buah saringan yaitu saringan kasar dan saringan halus. Saringan kasar berfungsi untuk memisahkan padatan yang berukuran besar dalam air limbah penyamakan kulit seperti potongan kulit, sedangkan saringan halus berfungsi untuk menyaring padatan yang lebih halus seperti bulu. Saringan ini berbentuk jeruji-jeruji. Proses penyaringan menjadi penting untuk memudahkan proses pengolahan air limbah, melindungi peralatan mekanik dari kerusakan karena adanya air limbah yang masih mengandung padatan serta menghindari terjadinya penyumbatan pada sistem distribusi air limbah.

c. Bak Equalisasi

Air limbah yang telah disaring selanjutnya di alirkan ke bak equalisasi. Bak ini berfungsi untuk menampung air limbah dan menghomogenkan atau menetralkan air limbah dengan pemberian $\mathrm{H} 2 \mathrm{SO} 4$ jika $\mathrm{pH}$ terlalu tinggi dan $\mathrm{NaOH}$ jika $\mathrm{pH}$ air terlalu rendah. Limbah dari bak equalisasi kemudian dipompa ke ke unit-unit berikutnya agar aliran stabil. Pengadukan dilakukan menggunakan mixer. Terdapat 4 bak equalisasi, namun hanya 2 bak yang berfungsi atau digunakan. Bak ini terbuat dari beton dengan ukuran diameter $30 \mathrm{~m}$ dan tinggi $5 \mathrm{~m}$, dengan kapasitas 25m3/jam. Bak equalisasi ini memiliki temperatur $40^{\circ} \mathrm{C}-43^{\circ} \mathrm{C}$ dengan waktu tinggal 30 menit.

d. Chemical Proses

Selain penanganan berupa penambahan bahan kimai $\mathrm{H} 2 \mathrm{SO} 4$ atau $\mathrm{NaOH}$, terjadi pula proses yang dinamakan proses koagulasi dan flokulasi.

1) Koagulasi

Proses ini menggunakan dua buah bak yang dilengkapi pengaduk cepat dalam setiap baknya dan ditambahkan koagulan. Koagulan ini akan mengikat partikel-partikel halus untuk membentuk flok-flok yang mampu mengendap di primary clarifer. bak koagulan ini memiliki ukuran dengan $\mathrm{p}=3 \mathrm{~m}, \mathrm{l}=2 \mathrm{~m}, \mathrm{t}=$ $5 \mathrm{~m}$ dengan volume $=30 \mathrm{~m} 3$ dengan waktu tinggal 1 jam.

2) Flokulasi

Proses ini menggunakan dua buah bak yang dilengkapi satu buah pengaduk dengan kecepatan rendah setiap baknya. Apabila diperlukan, pada tahap ini ditambahkan flokulan (polimer). Bak flokulasi ini memiliki ukuran hampir sama dengan bak 
koagulasi hanya berbeda tinggi, bak flokulasi ini memiliki tinggi 6 , adapun waktu tinggal pada bak ini adalah 1 jam.

e. Bak Pengendap

Air limbah yang telah membentuk flok mengalir ke primary clarifer dan mengendap secara gravitasi. Endapan yang terjadi akan disapu oleh scraper menuju center column yang selanjutnya dipompa ke belt press. Airnya dipompa ke cooling water untuk didinginkan. Bak ini terbuat dari semen beton dengan ukuran $\mathrm{d}$ $=36 \mathrm{~m}, \mathrm{~h}=4,5 \mathrm{~m}, \mathrm{v}=4.500 \mathrm{~m} 3$ dengan waktu tinggal 2-4 jam.

f. Cooling Tower

Air yang dipompa dari bak pengendap didinginkan di cooling tower sampai suhu dibawah $37^{\circ} \mathrm{C}$. Suhu air limbah harus diturunkankarena bakteri pengurai limbah memiliki suhu optimal hidupnya pada $37^{\circ} \mathrm{C}$, diatas suhu tersebut bakteri akan shock bahkan mati. Pendinginan dilakukan dengan menggunakan exhouse fan yang berfungsi untuk menyedotudara panas dari air yang dijatuhkan melalui siripsirip cooling tower sehingga air yang jatuh berbentuk butiran-butiran kecil. Air limbah yang telah didinginkan akan mengalir ke bak aerasi untuk memperoleh perlakuan biologi.

g. Bak Aerasi

Bak Aerasi berisi air limbah yang bercampur dengan lumpur aktif. Lumpur aktif merupakan lumpur bakteri yang berfungsi untuk mengolah limbah. Di bak aerasi akan terjadi proses degradasi senyawa organik dalam air limbah oleh bakteri. Bak aerasi di PT Budi Makmur dilengkapi dengan 11 aerator yang dicelupkan dan dua buah mixer yang tidak disuplai oksigen. Aerator yang dicelupkan berfungsi untuk memecah udara menjadi gelembunggelembung udara yang lebih kecil, sedangkan sebagai sumber oksigen digunakan roots blower sebanyak 3 unit. Urea dan bakteri guard ditambahkan sebagai nutrisi bagi mikroorganisme pengurai limbah. Adapun waktu tinggal pada bak aerasi adalah 8 jam. h. Bak Lumpur Pengering

Lumpur yang dihasilkan pada bak aerasi kemudian masuk ke dalam bak lumpur pengering. Bak lumpur pengering ini berfungsi untuk mengeringkan lumpur sisa hasil pengolahan penyamakan kulit. Lumpur yang sudah kering bisa dimanfaatkan kembali untuk dibuat bahan baku batako.

\section{SIMPULAN DAN SARAN}

\section{A. Simpulan}

Dari penelitian yang telah dilakukan, penulis menyimpulkan:

1. PT Budi Makmur mengolah limbah cairnya dengan menggunakan 8 tahap yaitu: Aliran masuk (Bak Penampungan), Penyaringan, Equalisasi, Koagulasi - Flokulasi, Pengendapan, Cooling tower, Aerasi dan Pengeringan lumpur.

2. Sumber daya pengolahan limbah cair penyamakan kulit di PT Budi Makmur meliputi : Tenaga Pengolah, Alat Pengolahan Limbah Cair dan Bahan Pengolahan Limbah Cair.

3. Prosentase penurunan parameter limbah cair sebelum dan sesudah melalui proses pengolahan limbah cair penyamakan kulit yaitu : $\mathrm{COD}=$ $1.865 \mathrm{mg} / \mathrm{tt}(94,91 \%), \mathrm{BOD}=1.847$ $\mathrm{mg} / \mathrm{lt}(94,93 \%), \quad$ TSS $=644 \mathrm{mg} / \mathrm{lt}$ $(36,30 \%)$, dan $\mathrm{pH}=0,01 \mathrm{mg} / \mathrm{tt}(0,13 \%)$

\section{B. Saran}

1. Perlu dilakukan pemeliharaan bak pengolahan air limbah minimal sekali dalam sebulan.

2. Perlu memaksimalkan penggunaan bak equalisasi agar dapat terpakai dengan maksimal.

\section{DAFTAR PUSTAKA}

BAPEDAL DIY, 2001, "Program Kali Bersih (PROKASIH)", Yogyakarta

Bahri, 2009, Studi Pengolahan Limbah Cair Di IPLC Tahun 2009, Purwokerto: Kementerian Kesehatan RI Politeknik Kesehatan Semarang Jurusan Kesehatan Lingkungan Purwokerto 
Fajar Kurniawan, 2010, Studi Pengolahan Limbah Cair Domestik di Balai Instalasi Pengelolaan Air Limbah (IPAL) Sewo Bantul Yogyakarta Tahun 2010, Purwokerto: Kementerian Kesehatan RI Politeknik Kesehatan Semarang Jurusan Kesehatan Lingkungan Purwokerto

Herlambang Arie, Prasetiyo Susanto Joko, dkk, 2002, Teknologi Pengolahan Limbah Cair Industri, Jakarta Pusat : BPPT

Setiyono, Idaman Said Nusa, 2004, Pedoman Teknis Pengelolaan Limbah Industri Kecil, Jakarta

Soeparman, Suparmin, 2001, Pembuangan Tinja Dan Limbah Cair, Jakarta : Penerbit Buku Kedokteran EGC
Sugiharto, 1987, Dasar - dasar Pengolahan Air Limbah, Jakarta : Universitas Indonesia

Tomi Hendartomo, 2003, Analisis Efisiensi dan Benevit Cost Ratio Pengoperasian Instalasi Pengolahan Air Limbah (IPAL) Industri Penyamakan Kulit Tahun 2003, Yogyakarta: Universitas Gajah Mada Yogyakarta

Widiarni Anugrah Safitri, 2012, Studi Pengolahan Limbah Cair Batik dengan Sistim Lahan Basah Buatan di Kelurahan Jenggot Kecamatan Pekalongan Selatan Kota Pekalongan Tahun 2012, Purwokerto: Kementerian Kesehatan RI Politeknik Kesehatan Semarang Jurusan Kesehatan Lingkungan Purwokerto 